\title{
Cognitive and psychological sequelae of hydrocephalus and spina bifida: turning interesting theoretical research into useful clinical intervention and guidelines
} JL Iddon*1,2, C Loveday ${ }^{1,2,3}$, JD Pickard ${ }^{2}$ and DJR Morgan ${ }^{1}$

\author{
Address: ${ }^{1}$ Department of Medicine \& Therapeutics, Level 4, Chelsea and Westminster Hospital, 369 Fulham Road, London, SW10 9NH, UK, \\ 2Department of Academic Neurosurgery (Box 167), Addenbrooke's Hospital, Cambridge, CB2 2QQ, UK and ${ }^{3}$ Department of Cognitive \\ Neuroscience, University of Westminster, Watford Road, Harrow, HA1 3TP, UK \\ Email: JL Iddon* - joiddon@aol.com \\ * Corresponding author
}

from 50th Annual Meeting of the Society for Research into Hydrocephalus and Spina Bifida

Cambridge, UK. 30 August - 2 September 2006

Published: 2I December 2006

Cerebrospinal Fluid Research 2006, 3(SuppI I):S32 doi:I0.1186/1743-8454-3-SI-S32

(c) 2006 Iddon et al; licensee BioMed Central Ltd.

\section{Background}

Ventricular shunts have significantly improved the prognosis of people with hydrocephalus and spina bifida; nevertheless, there are lifelong effects, which in many cases is associated with a cognitive profile of short term memory, attention and executive function difficulties (Iddon et al, 1996, 2001, 2003, 2004). There can also be psychological sequelae including depression and low self-esteem. The aim of this study is to develop clinical practice guidelines to inform intervention strategies to help patients and their carer to manage these difficulties.

\section{Materials and methods}

A three-stage project is being developed.

Stage 1: A survey will be carried out to ascertain the needs of the client group, including gaps in local service provision and the impact of cognitive and psychological difficulties on everyday lives.

Stage 2: Using data previously collected as well as new data, a detailed review will take place of specific cognitive difficulties and how these relate to everyday functions.

Stage 3: A cognitive training programme will be developed as a guideline for practical clinical intervention.

\section{Results}

Data will be presented, showing the unmet need of people with hydrocephalus and spina bifida $(\mathrm{N}=150$, range of IQ's). Preliminary results of the new project will be presented and discussed.

\section{Conclusion}

It is not possible to provide a complete psychological support for individuals with hydrocephalus attending one London hospital clinic for their annual multi-disciplinary review. However, this project aims to bridge the theoreti$\mathrm{cal} / \mathrm{clinical}$ gap we have previously identified in order to inform and guide their local services of the unmet needs of these clients, and to recommend appropriate interventions. This we anticipate will improve patients' quality of life. 